\title{
Monetary Policy and National Divergences in a Heterogeneous Monetary Union
}

\author{
C. Badarau-Semenescu \\ Université d'Orléans \\ N. Gregoriadis \\ Université d'Orléans \\ P. Villieu \\ Université d'Orléans
}

\begin{abstract}
In spite of the structural heterogeneity of the Eurozone, the main objective of the European Central Bank (ECB) is to preserve price stability for the union as a whole, and she pays full attention to Union-wide inflation and output, neglecting national divergences. In this paper, we wonder, at a theoretical level, about the social loss associated with such a "centralized" objective, and we show the existence of an "optimal" contract for the common central bank, which ensures a correct stabilization of national magnitudes. Furthermore, we show that social welfare does not necessarily improve if the ECB worries about inflation divergences without being concerned about output divergences in the Union.

- JEL Classification : E52, E58, F33

- Key Words: monetary policy, monetary union, optimal contract, inflation divergences, output divergences

*C. Badarau-Semenescu(Corresponding author): Laboratoire d'Economie d'Orléans (LEO), Université d'Orleans, Faculté de Droit, d'Economie et de Gestion, Rue de Blois BP. 6739, 45067 Orléans Cedex 2, France, Tel: 0033686112681, e-mail: florina-cristina.semenescu@univ-orleans.fr, N. Gregoriadis: Laboratoire d'Economié d'Orléans (LEO), Université d'Orleans, Faculté de Droit, d'Economie et de Gestion, Rue de Blois BP-6739, 45067 Orléans Cedex 2, France, P. Villieu: Laboratoire d'Economie d'Orléans (LEO), Université d'Orléans, Faculte de Droit, d'Economie et de Gestion, Rue de Blois BP6739, 45067 Orleans Cedex 2, France.

(c)2009-Center for International Economics, Sejong Institution, Sejong University, All Rights Reserved.
\end{abstract}




\section{Introduction}

It is widely recognized that the Euro area is an asymmetric monetary Union composed of countries with heterogeneous structures of financial, goods and labour markets, facing asymmetric shocks. The enlargement of the European Monetary Union (EMU) towards the Eastern European countries is likely to further amplify those heterogeneities. However, the policy of the European Central Bank (ECB) mainly focused on price stability for the whole Euro area, paying attention to the Union-wide output and especially inflation, but disregarding structural asymmetries within the Union. ${ }^{1}$ Under these circumstances the fundamental question that arises is whether the policy of a common central bank should capture national divergences, and, if so, in which extent?

This question has been addressed in the recent literature on the optimal monetary policy in an asymmetric monetary Union. First, empirical results show that considering national variables may enhance welfare gains for the Union. ${ }^{2}$ In particular, Brissimis \& Skotida (2008) report that the ECB can achieve significant gains by taking into account the heterogeneity of economic structures of member countries. Aksoy, De Grauwe \& Dewachter (2002) show that asymmetric shocks and divergent propagation of shocks in output and inflation are potential causes of tension, likely to influence the conduct of the common monetary policy. Second, using theoretical models, Gros \& Hefeker (2002) and De Grauwe \& Senegas (2006) find that the presence of structural asymmetries in the interest rate transmission requires a monetary policy which takes into account national data besides aggregate variables. Nevertheless, these studies consider output divergences only, while the common inflation rate is set by monetary policy. ${ }^{3}$ Our

\footnotetext{
${ }^{1}$ Two main criticisms are addressed to the ECB policy. The first one concerns the absence of an objective of sustaining the economic activity in the monetary policy loss function. The second one expresses a serious concern over the bear use of national information and its almost exclusive analysis based on centralized variables. In this paper, we focus on the second criticism. Effectively, the Article 105 of the Treaty states that the main objective of the ECB policy is to preserve the price stability, but it recognizes that it could also contribute, without prejudice to its primary objective, to sustain the real activity. Recent empirical data seem to prove that the ECB actually gives some weight to output stabilization (De Grauwe, 2007).

${ }^{2}$ This idea appears in De Grauwe (2000), Monteforte \& Siviero (2002) or Angeloni et al. (2002), for example. On the contrary, De Grauwe \& Piskorski (2001) consider that policies based on union-wide or on national aggregates yields stabilization performances that are quite similar. Heineman \& Hufner (2004) show, however, that the conventional Taylor rules that rely solely on Eurozone variables might be biased by the fact that, in practice, the members of the Governing Council of the ECB do not ignore the specific goals of their home country.
} 
study extends this literature in two ways. On the one hand, we generalize the results on the benefits of a monetary policy based on national information by controlling for inflation divergences. ${ }^{4}$ On the other hand, we propose a simple formulation of the optimal monetary policy, by means of an optimal contract that can be delivered to the common central bank.

We allow for two sources of heterogeneity in the Union: a) a simple structural asymmetry in the transmission channel of the common interest rate to aggregate demand, ${ }^{5}$ and b) idiosyncratic supply and demand shocks. ${ }^{6}$ Monetary policy is designed by a common central bank, only concerned about average variables (inflation and output-gap). In the model, the central bank possesses its own loss function (called "centralized" loss function), which differs from the Union loss function given by the average of national loss functions (called "cooperative" loss function). As in previous studies, compared to the "centralized" regime, the "cooperative" monetary strategy is always welfare improving. However, the inefficiency associated with a "centralized" monetary policy design can be easily removed by setting an "optimal contract" for the central bank. This optimal contract penalizes the common central bank for inflation and output divergences in the Union. The penalties imposed on inflation (respectively on output) divergences simply correspond to the relative weight of inflation (respectively output) in the social welfare function. The interpretation of the optimal contract is straightforward: if the common central bank is adequately penalized for inflation and output differentials, monetary policy takes into account the particular situation of each country, and reaches the Union-wide first best.

However, this result must receive some qualifications. First, the optimal contract is not beneficial to all Member-States. Setting a contract for the central bank may be a source of conflicts within the Union, even if it is an optimal one for the Union as a whole. Second, optimal penalties take simple values only if the member-states and the central bank share the same relative preferences for output and inflation

\footnotetext{
${ }^{3}$ Yet, output and inflation divergences are well documented in the Euro area (see, e.g. Angeloni \& Ehrmann, 2004; Musso \& Westermann, 2005), and the ECB mainly wonders about inflation divergences, with few or no reference to output divergences (see ECB, 2005, for example).

${ }^{4}$ With the notable exception of Gros \& Hefeker (2007), the previous studies do not study this feature

${ }^{5}$ In the EMU countries, the relative size of the "credit channel" or "interest channel" may produce divergent effects of monetary policy impulses (Issing \& al., 2001; Mojon \& Peersman, 2001). The enlargement of EMU will also increase uncertainty about the transmission channel (Hefeker, 2004).

${ }^{6}$ Gros \& Hefeker (2002) and De Grauwe \& Senegas (2006) consider only symmetric shocks. However, as we will see, the mix between symmetric and asymmetric shocks strongly affects the form of the central bank contract.
} 
stabilization. In the opposite case, an optimal contract can still be found, but it becomes more complicated, and the penalties are model-dependent. Third, the common central bank may be only concerned with inflation differentials. The monetary policy reports of the ECB prove that this could be the case in the Euro area. Under this assumption, no optimal contract exists, but a "second best" contract can minimize the Union-wide social loss function. The model shows that, if the central bank ignores output divergences, the second best coefficient for inflation divergences is not necessarily positive. Thus, attempting to reduce inflation divergences in a heterogeneous Union does not necessarily represent an advisable practice, unless it is supported by an output divergence-oriented device.

This reminder of the paper is structured as follow. Section II presents the model. Section III investigates the cost of a centralized monetary policy design, relative to the optimal "cooperative" solution. In section IV we assess the optimal contract for the common central bank, while in section V and VI we study how the optimal contract must be changed when the central bank does not share social preferences for the stabilization of output relative to inflation, and the features of "second best" contracts when it disregards output divergences, respectively. The final section concludes.

\section{The Model}

Our model depicts a closed Monetary Union made up of a continuum of small open economies represented by the unit interval. ${ }^{7}$ All countries are of measure zero and are indexed by $i$. Supply functions are defined by:

$$
y_{i}^{s}=\alpha \pi_{i}+\mu_{i}^{s}
$$

where $\pi_{i}, y_{i}^{s}, \mu_{i}^{s}$ relate to the country $i$ and define the aggregate supply, the inflation rate and a white noise supply shock with variance $\sigma_{\mu_{i}^{s}}^{2}$, respectively. ${ }^{8}$ All variables

\footnotetext{
${ }^{7}$ We use a continuum of countries to ensure the compatibility of our model with the microfounded framework provided by Gali \& Monacelli (2008). All results are obviously unchanged in a discrete sum formulation.

${ }^{8}$ Compared to Gros \& Hefeker (2002) and De Grauwe \& Senegas (2006), we suppose here that inflation rates may be different across countries. It is an important characteristic of our model, since we want to study the optimal way for the common central bank to take account of inflation divergences in the Union. Thus, we cannot suppose, as these authors do, that the central bank directly controls "the" inflation rate. In contrast, we must specify demand functions and study the monetary transmission process.
} 
are specified in log-deviations from their equilibrium levels (in particular, the natural level of output is zero, and all expected quantities are set to zero). Thus, relation (1) depicts a "Lucas supply function", in which equilibrium output can exceed natural product only when some "surprises" are present, either because of an exogenous supply shock or an inflation surprise which produces an ex post under-indexation of wages.

In order to focus on heterogeneity in the Union, we specify very simple demand functions. In country $i$, the demand depends on the Union-wide interest rate $(r)$. Since all expected quantities are set to zero, expected inflation (in deviation from its equilibrium value) is zero, and $r$ denotes either the real or the nominal interest rate, considered the monetary policy instrument set by the common central bank (hereafter CCB). The demand also depends on competitiveness, measured by the real exchange rate. Since nominal exchange rate is irrelevant in a closed Monetary Union, competitiveness passes only through prices differentials, namely the relative price level between country $i$ and the other countries of the Union. In deviations from equilibrium, price differentials are equivalent to inflation differentials (because past equilibrium variables are normalized to zero), so a good indicator of country $i$ competitiveness is the inflation differential: $\pi$ - $\pi_{i}$, where $\pi=\int_{0}^{l} \pi_{i} d i$ is the average inflation rate in the Union. Demand functions are also affected by a white noise demand shock $\left(\mu_{i}^{d}\right)$ with variance $\sigma_{\mu_{i}^{d}}^{2}$ :

$$
y_{i}^{d}=\beta\left(\pi-\pi_{i}\right)-b_{i} r+\mu_{i}^{d}
$$

In addition to idiosyncratic shocks, we introduce some "structural" heterogeneity in the Union, and more precisely in the monetary policy transmission channel $\left(b_{i}\right){ }^{9}$ In order to deal with « pure » heterogeneity effects, independently of average effects, we define the coefficient $b_{i}$ in deviation from its mean. Let $b=\int_{0}^{b} b_{i} d i$ be the average interest-elasticity of demand in the Union; we define $b_{i}=\left(1+\varepsilon_{i}\right) b$ as the country- $i$ specific component of the monetary policy transmission channel, with $\varepsilon_{i} \in[-1,1]$ and $\int_{0}^{l} \varepsilon_{i} d i=0$. In what follows, "structural" heterogeneity in the Union will be synthesized by the following index of dispersion: $\Sigma^{2} \equiv \int_{0}^{l} \varepsilon_{i}^{2} d i \in[0,1]$.

${ }^{9}$ In a separate Technical Appendix (available on request), we detail the microfoundations of the equations (1) and (2) above. In synthesis, like in Walsh (2001) or Gali \& Monacelli (2008), supply functions (1) come from the maximization of profit by competitive firms, with predetermined wages. The demand functions (2) can explicitly be derived by introducing slight changes in Gali \& Monacelli (2008). In addition, we disregard public spending issues; see for example Minea \& Villieu (2009). 
All shocks $\mu_{i}$ (and, more generally, all variables of the model) can be represented as the sum of an average component $(\mu)$, affecting every country in the same way, and a deviation component $\left(\bar{\mu}_{i}=\mu_{i}-\mu\right)$, specific to the country $i$ : $\mu_{i} \equiv \mu+\bar{\mu}_{i}\left(\right.$ where $\left.\int_{0}^{l} \bar{\mu}_{i} d i=0\right)$. We design as "symmetric" the component of shocks that affects every country in the same way $\left(\mu^{s}, \mu^{d}\right)$, and as "asymmetric" the specific component of shocks $\left(\bar{\mu}_{i}^{s}, \bar{\mu}_{i}^{d}\right)$.

To solve the model, we write equilibrium in average $\left(y^{s}=y^{d}\right)$ and in deviations $\left(\bar{y}_{i}^{s}=\bar{y}_{i}^{d}\right)$. Appendix $A$ shows that equilibrium solutions are independent of coefficient $b$, so we can normalize this coefficient to: $b=1$. We obtain the following symmetric (or average) and asymmetric (or specific) components of inflation:

$$
\begin{gathered}
\pi=\frac{\mu^{d}-\mu^{s}-r}{\alpha} \\
\bar{\pi}_{i}=\frac{\bar{\mu}_{i}^{d}-\bar{\mu}_{i}^{s}-\varepsilon_{i} r}{\alpha+\beta}, \forall i
\end{gathered}
$$

and we can easily compute Union product, on average $\left(y=\int_{0}^{1} y_{i} d i\right)$ and in deviation:

$$
\begin{gathered}
y=\alpha \pi+\mu^{s}=\mu^{d}-r \\
\bar{y}_{i}=\alpha \bar{\pi}_{i}+\bar{\mu}_{i}^{s}=\frac{\alpha \bar{\mu}_{i}^{d}-\alpha \varepsilon_{i} r+\beta \bar{\mu}_{i}^{s}}{\alpha+\beta}, \forall i
\end{gathered}
$$

In equation (4a), we can notice that Union average income does not depend on heterogeneity coefficients $\left(\varepsilon_{i}\right)$. This is also the case for all average variables in the Union. Equation (4b) shows that the transmission channel of the common interest rate is asymmetric, because of the heterogeneity of the Union.

We suppose that each country of the Union is endowed with a social loss function that depends on stabilization of income and inflation:

$$
L_{i}=\frac{1}{2}\left[\lambda y_{i}^{2}+\pi_{i}^{2}\right]
$$

where depicts social preferences for income relative to inflation stabilization. We also suppose that $\lambda$ is the same in all countries, in order to focus on "structural" heterogeneity in the Union. ${ }^{10}$ The Union-wide social loss is: ${ }^{11}$

$$
L^{U}=\int_{0}^{L} L_{i} d i
$$


In contrast with this social loss function, based on the average of national loss functions, we suppose that the CCB chooses the Union-wide interest rate $r$, in order to minimize a loss function that depends on the stabilization of income and inflation, based on the average variables of the Union:

$$
L^{c}=\frac{1}{2}\left[\tilde{\lambda} y^{2}+\pi^{2}\right]
$$

In the Euro zone, for example, the decisions of the ECB are based on average euro variables and not on national loss functions (see the Introduction). In our model, we depict such a situation by the fact that the CCB minimizes a "centralized" loss function $\left(L^{c}\right)$ and not the Union-wide social loss function, which is a "cooperative" loss function $\left(L^{U}\right)$. We first suppose that the CCB shares the social preference parameter for the stabilization of output relative to inflation $(\tilde{\lambda}=\lambda)$, in order to focus on the impact of "centralized" versus "cooperative" designs of monetary policies. In section $\mathrm{V}$, we consider the alternative case in which the CCB possesses distinct preferences $(\tilde{\lambda} \neq \lambda)$.

To keep the model simple, we also choose to focus exclusively on a stabilization problem for monetary policy, and we ignore a possible inflation bias problem that emerges when the CCB defends an output target higher than the natural product (here zero). In fact, this well-known inflation bias can be removed by setting an optimal contract that penalizes the CCB from inflation deviations, as showed by Walsh (1995). ${ }^{12}$ In our model, the minimization of (7) relative to (6) does not raise a problem of systematic bias, but a stabilization problem for monetary policy. As a result, the CCB preferences for the stabilization of output and inflation must be modified, by a kind of "quadratic" contract, since only quadratic contracts may affect the stabilization properties of monetary policies. The intuition of our results in section IV is that the penalties on inflation and output divergences are precisely a kind of quadratic contract. Before analyzing such contracts, let us assess the cost of a "centralized" decision-making relative to a "cooperative" one.

\footnotetext{
${ }^{10}$ The heterogeneity of preferences is an important, but distinct, question. Our model describes a Union where there are no preference conflicts, but simply differences in the functioning of economies.

${ }^{11}$ Since we assume a union composed of a continuum of countries (see footnote 7), an integral appears in the social loss functions. However, we must underline that the resolution and all results of the model remain unchanged in a monetary union composed of a finite number of countries, like the EMU.

${ }^{12}$ Such an optimal contract results in a linear penalty on inflation In our model, if ${ }_{\tilde{\lambda}}$ is the output target of the common central bank, the optimal penalty for inflation deviations is: $c=\tilde{\lambda} k \alpha$, so that the CCB minimizes: $L^{c}=\frac{1}{2}\left[\lambda(y-k)^{2}+\pi^{2}+2 c \pi\right]$.
} 


\section{The Cost of a Centralized Monetary Policy}

Let us now characterize the inefficiencies associated to the minimization of (7) rather than (6), considering first that each Member State of the Union and the CCB share the same relative preferences for output and inflation stabilization $(\tilde{\lambda}=\lambda)$.

The CCB chooses the interest rate by minimizing (7), knowing the values of demand and supply shocks. The union-wide interest rate is thus (see Appendix A):

$$
r=r^{c}=\psi_{1}^{u} \mu^{s}+\psi_{2}^{c} \mu^{d}
$$

where: $\psi_{1}^{\varepsilon}=-1 / \lambda_{1}, \psi_{1}^{\varepsilon}=1$, and: $\lambda_{1}=1+\alpha^{2} \lambda$.

The optimal interest rate, issued by minimizing (6) with respect to $r$ is (Appendix A):

$$
r=r^{u}=\psi_{1}^{\mu} \mu^{s}+\psi_{2}^{\mu} \mu^{d}+\psi_{3}^{\mu} \Sigma_{\mu}^{s}+\psi_{4}^{\mu} \Sigma_{\mu}^{d}
$$

where: $\psi_{1}^{\prime \prime}=\psi_{1}^{\prime} a_{1} \lambda_{1} / a, \psi_{2}^{\prime \prime}=\psi_{2}^{\prime} a_{1} \lambda_{1} / a, \psi_{3}^{\prime \prime}=\lambda_{3} \alpha^{2} / a$ and $\psi_{4}^{\prime \prime}=\alpha^{2} \lambda_{1} / a$. All along the paper, we use the notations: $a_{1}=(\alpha+\beta)^{2}, a_{2}=\alpha^{2} \Sigma^{2}$ and: $a=\lambda_{1}\left(a_{1}+a_{2}\right)$; as well as : $\lambda_{1}=1+\alpha^{2} \lambda, \quad \lambda_{2}=1+\beta^{2} \lambda, \quad \lambda_{3}=\alpha \beta \lambda-1, \quad$ and $\quad \sum_{\mu}^{s} \equiv \int_{0}^{1} \varepsilon_{i} \mu_{i}^{s} d i$, $\Sigma_{\mu}^{d}=\int_{0}^{1} \varepsilon_{i} \bar{\mu}_{i}^{d} d i$

A direct comparison between (8) and (9) allows identifying the inefficiencies in monetary policy. The results are summarized by the following Proposition:

\section{Proposition 1:}

In a heterogeneous Monetary Union, symmetric shocks have to be less stabilized and asymmetric shocks have to be more stabilized than in a homogenous Union. The interest rate policy obtained by minimizing a "centralized" loss function, depending only on average magnitudes, involves an over-reaction to symmetric shocks and an insufficient reaction to asymmetric shocks.

\section{Proof:}

Concerning symmetric shocks, since: $a_{1} \lambda_{1} / a<1$, we have: $\left|\psi_{1}^{2}\right|<\left|\psi_{1}^{\mid}\right|$and: $\psi_{2}^{\prime \prime}<\psi_{2}^{2}$ if $\Sigma^{2}>0$. On the one hand, the reaction of interest rate to symmetric supply shocks is excessive with a centralized monetary policy relative to a cooperative one. As a result, the Union-wide average product will be insufficiently stabilized in (4a), while average inflation will be too much stabilized in (3a). On the other hand, 
in the cooperative regime, demand shocks should be perfectly stabilized if the monetary Union was homogenous $\left(\Sigma^{2}=0 \Rightarrow \psi_{2}^{\prime \prime}=1\right)$, but have to be only partially stabilized in a heterogeneous Union (since $\psi_{2}^{\prime \prime}<1$ if $\Sigma^{2}>0$ ). Yet, with a centralized loss function, the CCB fully stabilizes symmetric demand shocks, in spite of heterogeneity. As a result, average inflation and output in Union are to much stabilized, to the detriment of the stabilization of deviations $\left(\bar{y}_{i}\right.$ and $\left.\bar{\pi}_{i}\right)$. Therefore, concerning symmetric shocks, one needs a less reactive monetary policy in a heterogeneous monetary Union than in a homogenous Union.

Furthermore, by focusing on average variables of the Union, the CCB does not consider asymmetric shocks, while it should do under the optimal interest policy (see (8) and (9) where $\psi_{3}^{\prime \prime} \neq 0$ and $\psi_{4}^{\prime \prime} \neq 0$ ). Thus, asymmetric shocks are not sufficiently stabilized in the Union. Average output and inflation are not affected, but the use of a centralized loss function increases divergences in the area: national quantities are not properly stabilized.

Notice that in a homogenous Monetary Union $\left(\varepsilon_{i}=0, \forall i\right)$, our model would give rise to the well-known equivalence between minimizing $L^{U}$ or $L^{C}$ (Gros \& Hefeker, 2002; De Grauwe \& Senegas, 2006). Thus, if there was no cross-country divergence, monetary authorities could rely on a loss function based on area wide variables only, without implying any welfare loss in the Union. In a heterogeneous Union, on the contrary, the social loss will be higher with the interest rate rule (8) than with (9).

From the Union-wide welfare point of view, what matters is the ex ante (i.e. before knowing the value of shocks) value of the social loss function, namely $E L^{U}$, $E$ denoting the rational expectation operator. To simplify the model, we suppose in the main text that there is no demand shock. ${ }^{13}$ So, we henceforth neglect demand shocks, by setting from now: $\sigma_{\bar{\mu}_{i}}^{2}=\sigma_{\mu^{d}}^{2}=0, \forall i$. We will respectively refer to: $\sigma_{\mu}^{2}=\sigma_{\mu}^{2}$ and $\sigma_{\vec{\mu}_{i}}^{2}=\sigma_{\bar{\mu}_{i}}^{2}$ for the variances of symmetric and asymmetric components of supply shocks. In addition, to save notations, we also suppose that: $i$ ) specific and average components of supply shocks are independently distributed: $\left.\sigma_{\mu \overline{\mu_{i}}}=0, \forall i, i i\right)$ idiosyncratic supply shocks are independently distributed:

\footnotetext{
${ }^{13}$ Part $\mathrm{C}$ of our Technical Appendix explicitly proves that the stabilization of demand shocks do not raise specific question and the way demand shocks are handled can be viewed as a special case of supply shocks analysis. We thus concentrate our attention on supply shocks, which are a direct clause of concern for monetary policy. Since fiscal policies are unable to optimally stabilize supply shocks in the union, we do not explicitly introduce such policies in the model. However, national fiscal policies can be viewed as implicit policies which perfectly stabilize idiosyncratic demand shocks in the Union, explaining while both demand shocks and fiscal policies are not present in the model.
} 
$\sigma_{\bar{\mu}_{\bar{\mu}} \bar{\mu}_{i}}=0, \forall i$, and $\left.i i i\right)$ they have the same variance: $\sigma_{\vec{\mu}_{i}}^{2}=\sigma_{\bar{\mu}}^{2}, \forall i{ }^{14}$

Therefore, under the optimal interest rate policy $(9)$, the expected Union-wide social loss is: $E L^{U}\left(r^{u}\right)=X \sigma_{\mu}^{2}+\bar{X} \sigma_{\bar{\mu}}^{2}$. Under the centralized policy (8) the expected social loss becomes: $E L^{U}\left(r^{u}\right)=Y \sigma_{\mu}^{2}+\bar{Y} \sigma_{\bar{\mu}}^{2}$. Coefficients $X, \bar{X}, Y$ and $\bar{Y}$, computed in Appendix A, are such that: $Y>X, \bar{Y} \geq \bar{X}$, and we can easily verify that: $E L^{U}\left(r^{u}\right)<E L^{U}\left(r^{c}\right)$. Therefore, we obtain the value of the welfare differential: $\left(\Delta E L \equiv E L^{U}\left(r^{c}\right)-E L^{U}\left(r^{u}\right)\right)$

$$
\Delta E L^{U} \equiv(Y-X) \sigma_{\mu}^{2}+(\bar{Y}-\bar{X}) \sigma_{\bar{\mu}}^{2}=\frac{\alpha \Sigma^{2}\left[\Sigma^{2} \sigma_{\mu}^{2}+\lambda_{3}^{2} \sigma_{\bar{\mu}}^{2}\right]}{2 a_{1} \lambda_{1}\left(a_{1}+\alpha \Sigma^{2}\right)}
$$

When the Union is heterogeneous, both asymmetric and symmetric shocks are improperly stabilized with a centralized policymaking, as equation (10) clearly shows. A centralized monetary policy is unable to react to asymmetric shocks, but overreacts to symmetric shocks (Proposition 1). Symmetric shocks are not well stabilized with the centralized policymaking because, in a heterogeneous Union, the multipliers of symmetric shocks differ within the area (since the common interest rate reacts to symmetric shocks and the transmission channel of the interest rate to aggregate demand is asymmetric). Thus a centralized monetary policy cannot take account of this heterogeneity of multipliers.

Furthermore, we can obtain from equation (10): $\frac{d \Delta E L^{U}}{d \Sigma^{2}}>0$. Thus, the more heterogeneous the Union is, the higher the relative cost of a centralized policymaking will be. This finding holds independently of the nature of shocks (symmetric or asymmetric). Table 1 simulations clearly show that the welfare cost of a centralized monetary policy (relative to a cooperative one: $\Delta E L^{U} / E L^{U}$ ) may be quite high, reaching more than $10 \%$ of welfare if the Union is very heterogeneous.

It is thus quite obvious that, in a heterogeneous monetary union, the common central bank should take into account national divergences. However, proposing

Table 1. Social Loss Differential (in \%)

\begin{tabular}{ccccc}
\hline & $\sum^{2}=0.25$ & $\sum^{2}=0.5$ & $\sum^{2}=0.75$ & $\sum^{2}=1$ \\
\hline$\lambda=0.5$ & 0.27 & 0.96 & 1.96 & 2.67 \\
$\lambda=1$ & 0.65 & 1.42 & 2.27 & 3.17 \\
$\lambda=3$ & 3.29 & 6.19 & 8.78 & 11.11 \\
$\lambda=5$ & 4.98 & 9.46 & 13.51 & 17.19 \\
\hline
\end{tabular}

For $\alpha=2, \beta=1$ and $\sigma_{\bar{\mu}}^{2}=\sigma_{\mu}^{2}$

\footnotetext{
${ }^{14}$ These assumptions are only notation-saving assumptions, with no generality loss; see Appendix A for
} the general resolution of the model 
the central banker an aggregate loss function defined by the average of the national loss functions (see De Grauwe \& Senegas (2006) for example) is difficult to be accepted, because it is too complicated to respect the transparency principle of the monetary policy. In this context, the section III of this paper searches for an alternative solution coming from a kind of contract for the monetary policy.

\section{Introducing Aversion to Divergences in the Central Bank Loss Function}

This section seeks for a contractual solution to the issue of the centralized monetary policy. Although Walsh (1995) discussed linear contracts as "workarounds" for the lack of commitment devices, Herrendorf \& Lockwood (1997) showed that only quadratic contracts are optimal to solve a stabilization problem of monetary policy. In this model, the commitment vs. discretion issue is not addressed, because the problem is only the difference between the society's preferences and those of the $\mathrm{CCB}$, who does not adequately fight divergences in the Union. Consider that the Union, acting as the "principal", can delegate monetary policy to the CCB (the "agent"). By setting an optimal contract, the "principal" can twist the CCB preferences, to obtain the social optimum. We describe such solutions by the fact that, beyond stabilizing average variables in the Union, the CCB attempts to stabilize inflation and income differentials.

\section{A. General Formulation of the Problem}

In the present model, by focusing exclusively on aggregate magnitudes, the CCB cannot obtain the optimal solution. The goal of the "principal" is to force the "agent" (CCB) to be more reactive to national divergences, by imposing adequate “penalties" $(p()$.$) , so that he minimizes: L^{c}\left(\pi_{i}, y_{i}\right)+p\left(\pi_{i}, y_{i}\right)$. Of course, if the CCB loss function $L^{C}\left(\pi_{i}, y_{i}\right)$ is and the social loss function is $L^{U}\left(\pi_{i}, y_{i}\right)$, a trivial optimal penalty that could be added to the CCB loss function is: $p^{*}\left(\pi_{i}, y_{i}\right)=L^{U}\left(\pi_{i}, y_{i}\right)-L^{C}\left(\pi_{i}, y_{i}\right)$. Nevertheless, such a penalty would be difficult to implement, in particular because it depends on CCB's preferences that are possibly non-observable by the principal. Thus, we search for another form of penalties that rely on simple variables, easy to check. Such penalties should make the optimal contract feasible, verifiable, and compatible with the transparency principle of monetary policy. Suppose for example that the principal imposes linear penalties to the $\mathrm{CCB}$ depending on inflation and output differentials, measured as the cross 
section standard error of these variables. ${ }^{15}$ The penalties represent an additional cost for the $\mathrm{CCB}$ and provide an incentive to fight divergences in the Union. ${ }^{16}$ The CCB loss function becomes:

$$
L^{c}=\frac{1}{2}\left[\lambda y^{2}+\pi^{2}+\theta_{y} \bar{y}^{2}+\theta_{\pi} \bar{\pi}^{2}\right]
$$

where $\theta_{y}$ and $\theta_{\pi}$ are the penalties for divergences in the contract for the central banker (or, equally, the coefficients of aversion towards income and inflation divergences in the CCB loss function). In this section, we search for optimal values for $\theta_{y}$ and $\theta_{\pi}$. The following proposition shows that we can find a simple optimal contract for the CCB.

\section{Proposition 2:}

If the different Member States of the monetary Union and the CCB share the same preferences for stabilization of output and inflation ( $\lambda$ and 1 , respectively), the first best solution for monetary policy can be obtained by an optimal contract that penalizes the CCB for inflation and output divergences. In the optimal contract, the penalties imposed on national divergences correspond to the relative weight of each variable in the social welfare function. Thus, the optimal contract for the CCB is such as: $\theta_{y}^{*}=\lambda$ and $\theta_{\pi}^{*}=1$.

\section{Proof:}

By minimizing (6) with respect to $r$, we obtain:

$$
\frac{\partial L^{c}(r)}{\partial r}=y \int_{0}^{1} y_{i} \frac{\partial y_{i}}{\partial r} d i+\int_{0}^{1} \pi_{i} \frac{\partial \pi_{i}}{\partial r} d i
$$

By minimizing (11) with respect to $r$ and rearranging, we obtain:

$$
\frac{\partial L^{C}(r)}{\partial r}=y\left(\lambda-\theta_{y}\right) \frac{\partial y}{\partial r}+\pi\left(1-\theta_{\pi}\right) \frac{\partial \pi}{\partial r}+\theta_{y} \int_{0}^{1} y_{i} \frac{\partial y_{i}}{\partial r} d i+\theta_{\pi} \int_{0}^{l} \pi_{i} \frac{\partial \pi_{i}}{\partial r} d i
$$

We can easily observe that expressions (12a) and (12b) are identical if $\theta_{y}=\lambda$

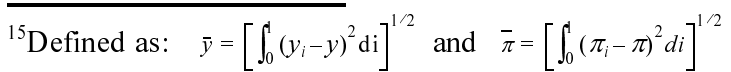

${ }^{16}$ Such penalties on inflation and output differentials look like a "quadratic" contract for central banker and correspond to changing preferences for the stabilization of divergences relative to the stabilization of Union-wide magnitudes. One can also notice the analogy with the analysis of Rogoff (1985), in which relative preferences for the stabilization of output relative to inflation have to be changed
} 
and $\theta_{\pi}=1$, so are loss functions (6) and (11). Thus, under the optimal contract, the centralized monetary regime with aversion to divergences is efficient and leads to the optimal regime. ${ }^{17}$

Proposition 2 shows that a simple "optimal contract" for the CCB can enforce the optimal solution. This result is similar to Walsh (1995), except that Walsh deals with inflation bias of monetary policy, while we exclusively deal with a stabilization problem. The interpretation of the "optimal contract" is straightforward: for monetary policy to take account of Union heterogeneity, one has to encourage the CCB to feel some aversion to inflation and output divergences. If the degree of aversion to divergences is well defined, as in the optimal contract, the common monetary policy produces the first best. ${ }^{18}$

\section{An illustration}

As we have seen, Proposition 2 is established for a general case. In our model, minimizing (11) provides the following relation, in place of (8):

$$
r=r^{c}=\psi_{1} \mu^{s}+\psi_{2} \mu^{d}+\psi_{3}^{s} \Sigma_{\mu}^{s}+\psi_{4}^{s} \Sigma_{\mu}^{d}
$$

with: $\psi_{1}^{\varepsilon}=-a_{1} \Phi, \psi_{2}^{2}=a_{1} \lambda_{1} \Phi, \psi_{3}^{\varepsilon}=\alpha^{2}\left(\lambda_{3}+\phi_{2}\right) \Phi$ and: $\psi_{4}^{\varepsilon}=\alpha^{2}\left(\lambda_{1}+\phi_{1}\right) \Phi$, and we use the notation: $\phi_{1}=\alpha^{2}\left(\theta_{y}-\lambda\right)+\theta_{\pi}-1, \phi_{2}=\alpha \beta\left(\theta_{y}-\lambda\right)+1-\theta_{\pi}$, and: $\Phi=\left(a+a_{2} \phi_{1}\right)^{-1}$.

One can easily verify that (13) corresponds to (9) if $\theta_{y}^{*}=\lambda$ and $\theta_{\pi}^{*}=1$, and to (8) if $\theta_{y}=\theta_{\pi}=0$. Reintroducing (13) into equilibrium values of inflation and output, we can express the expected social loss $E L^{U}$ for any values of $\theta_{y}$ and $\theta_{\pi}$ : $E L^{U}\left(r^{c}\right)=Z \sigma_{\mu}^{2}+\bar{Z} \sigma_{\bar{\mu}}^{2}$, where Coefficients $Z$ and $\bar{Z}$ are computed in Appendix A. ${ }^{19}$ The differential of welfare associated with a centralized policymaking compared to a cooperative one is now:

$$
\Delta E L=E L^{U}\left(r^{c}\right)-E L^{U}\left(r^{u}\right)=(Z-X) \sigma_{\mu}^{2}+(\bar{Z}-\bar{X}) \sigma_{\bar{\mu}}^{2}
$$

\footnotetext{
${ }^{17}$ Notice that this result does not depend on a particular form of supply or demand functions: the optimal contract in Proposition 2 is not model dependent.

${ }^{18}$ Menguy (2008) discusses an alternative solution to reduce the inefficiencies associates to the aggregate regime by modifying the weight given to each country in the definition of the CCB aggregate objectives. However, this solution does not represents a "first best" and Badarau \& all. (2008) showed that the choice of an optimal contract (similar to this one) could improve the social welfare of the union for all weights used by the CCB in the definition of the aggregate magnitudes.
} 
where: $-X=a_{1} a_{2}^{2}\left(\phi_{1}\right)^{2} \Phi^{2} / 2 a \alpha^{2} \geq 0, \bar{Z}-\bar{X}=a_{2}\left[\lambda_{1}(\alpha+\beta) \phi_{2}+\alpha a_{2} \phi_{3}\right]^{2} \Phi^{2} / 2 a \geq 0$; and we use the notation: $\phi_{3}=\left(\theta_{y}-\lambda\right)-\lambda\left(\theta_{\pi}-1\right)$.

Relation (14) clearly shows that the centralized regime improperly stabilizes both symmetric and idiosyncratic shocks, when the Union is heterogeneous. Let us deal with these two questions separately.

Concerning the symmetric component of supply shocks, a centralized policymaking reaches the same social loss than the optimal one $(X=Z)$ if $\phi_{1}=0$, namely if:

$$
\theta_{\pi}=\theta_{\pi}^{s}=1-\alpha^{2}\left(\theta_{y}-\lambda\right)
$$

This value is the one that minimizes the social loss function $\left(d E L^{U}\left(r^{c}\right) / d \theta_{\pi}=0\right)$, if there is no asymmetric shock $\left(\sigma_{\bar{\mu}}^{2}=0\right)$.

Concerning the asymmetric component of supply shocks, a centralized policymaking reaches the same social loss than the optimal one if $\bar{X}-\bar{Z}$, namely if:

$$
\theta_{\pi}=\theta_{\pi}^{i}=1+\alpha^{2} \Omega\left(\theta_{y}-\lambda\right)
$$

where: $\Omega=\frac{a_{2}+\beta(\alpha+\beta) \lambda_{1}}{\alpha(\alpha+\beta) \lambda_{1}+\lambda \alpha^{2} a_{2}}$. This value minimizes the social loss function $\left(d E L^{U}\left(r^{c}\right) / d \theta_{\pi}=0\right)$ if there is no symmetric shock $\left(\sigma_{\mu}^{2}=0\right)$.

The intersection of (15) and (16) provides the optimal penalties $\theta_{y}^{*}=\lambda$ and $\theta_{\pi}^{*}=1$, which insure appropriate stabilization of both types of supply shocks.

We can notice that: $\theta_{\pi}=\theta_{\pi}^{a}=1$ if $\theta_{y}=\lambda$, finding the optimal contract of Proposition 2. But for non-optimal values of the CCB aversion for output divergences (that is $\theta_{y} \neq \lambda$ ), there is a conflict between stabilizing symmetric and asymmetric components of supply shocks. In effect, $\theta_{\pi}$ negatively depends on $\theta_{y}$, while $\theta_{\pi}^{*}$ positively depends on it.

This characteristic can be explained as follows. With a centralized monetary policy, the interest rate reacts too much to symmetric supply shocks, as we have seen in Proposition 1. Raising the penalty on inflation divergences lowers the response of the interest rate to symmetric shocks and has a stabilizing effect on output differentials in the Union (in $4 b$ ). Thus, the penalty on output divergences can decrease. For symmetric supply shocks, both penalties are substitutable, thus

${ }^{19}$ Notice that $Z=X$ and $\bar{Z}=\bar{X}$, for $\theta_{y}=\lambda$ and $\theta_{\pi}=1$, and that $Z=Y$ and $\bar{Z}=\bar{Y}$, for $\theta_{y}=\theta_{\pi}=0$. 
$\theta_{y}$ and $\theta_{y}$ are negatively linked. On the contrary, for asymmetric supply shocks, both penalties are complementary and the centralized monetary policy gives rise to an insufficient stabilization of these shocks. Introducing a penalty on one differential (inflation or output) increases the variability of the interest rate, thus raising the other differential. So, a suitable stabilization of both objectives simultaneously requires $\theta_{y}$ and $\theta_{\pi}^{a}$ to move in the same direction. Thus, if $\theta_{y}<\lambda$, situation favoured in section $\mathrm{V}$, stabilizing symmetric supply shocks calls for a higher than one coefficient of aversion to inflation divergences $\left(\theta_{\pi}>1\right)$, but stabilizing asymmetric supply shocks requires a lower than one coefficient of aversion to inflation divergences $\left(\theta_{\pi}^{x}<1\right)$. The reverse is true if $\theta_{y}<\lambda$. Section $\mathrm{V}$ below studies the potential conflict between stabilizing symmetric/asymmetric shocks when optimal penalties cannot be implemented.

\section{B. National Losses under the "Optimal" Contract}

A central question about the feasibility of the optimal contract for the $\mathrm{CCB}$ concerns its effects on national welfare. Appendix $B$ computes the welfare differential of a particular country $i,\left(\Delta E L_{i}=E L_{i}^{c}-E L_{i}^{u}\right)$, between a centralized regime without penalty $\left(\theta_{\pi}=\theta_{y}=0\right)$ and the optimal (from the Union-wide point of view) regime with penalties $\theta_{\pi}^{*}=1$, and $\theta_{y}^{*}=\lambda$. Appendix $B$ also shows that: $\operatorname{Sign}\left(\Delta E L_{i}\right)=\operatorname{Sign}\left(\varepsilon_{i}-\bar{\varepsilon}\right)$, where: $\bar{\varepsilon}=\frac{\alpha(\alpha+\beta) \Sigma^{2}}{2(\alpha+\beta)^{2}+\alpha^{2} \Sigma^{2}} \in[0,1]$.

Since $\int_{0}^{1} \varepsilon_{i} d i=0$, there is at least one country for which: $\varepsilon_{i}<0<\bar{\varepsilon}$. Thus, the optimal contract is not beneficial for all participants to the Union.

Countries with high sensitivity to the common interest rate $\left(\varepsilon_{i}>\bar{\varepsilon}\right)$ will prefer the optimal monetary policy $\left(\Delta E L_{i}>0\right)$, but countries with low sensitivity to the common interest rate $\left(\varepsilon_{i}>\bar{\varepsilon}\right)$ will prefer the centralized monetary policy $\left(\Delta E L_{i}>0\right)$. This result can be explained as follows. First, as we have seen, the optimal policy is less concerned by the stabilization of symmetric shocks than the centralized policy. Countries in which the interest rate elasticity is low $\left(\varepsilon_{i}>\bar{\varepsilon}\right)$ prefer a policy that strongly responds to shocks, and are worse under the optimal regime. Second, the centralized policy does not react to asymmetric shocks, while the optimal policy does. Country $i$ takes benefits from the optimal policy because it stabilizes its own asymmetric shock, but at the same time, suffers from the fact that the Union-wide interest rate reacts to shocks in other countries, which destabilizes country $i$ variables. The higher the interest rate elasticity of aggregate demand is, the more the optimal policy stabilizes country $i$ idiosyncratic shock. So, only 
countries in which the interest rate elasticity is high $\left(\varepsilon_{i}>\bar{\varepsilon}\right)$ are better under the optimal regime.

Therefore, modifying CCB preferences, even to implement the optimal contract, can be a source of potential conflicts among Member States. Since Union-wide benefits exist, this limitation does not rule out the interest of an optimal contract. The welfare gain for countries that take advantage of this contract exceeds the welfare loss for the others and, consequently, one could imagine a compensation system for the last ones. In other words, even if the contract is not optimal at a national level, it could become beneficial to all member states of the Union if a compensation scheme could be implemented.

\section{The Optimal Contract with Independent Central Bank Preferences for Output and Inflation Stabilization}

One important shortcoming about Proposition 2 is that the different Member States of the Union and the CCB must share the same preferences. In the opposite case, it is still possible to find an optimal contract, which removes the inefficiency associated with a centralized monetary policy, but this contract is more complicated and the penalties towards inflation and output divergences become modeldependent.

Consider now that the $\mathrm{CCB}$ possesses its own preferences for the stabilization of output relative to inflation, namely: $\tilde{\lambda} \neq \lambda$. The objective of the CCB becomes:

$$
L^{c}=\frac{1}{2}\left[\tilde{\lambda} y^{2}+\pi^{2}+\theta_{y} \bar{y}^{2}+\theta_{\pi} \bar{\pi}^{2}\right]
$$

The interest rule obtained by minimizing of (11) is analogous to equation (13) below. $^{20}$

$$
r=r^{c}=\tilde{\psi}_{1}^{c} \mu^{s}+\tilde{\psi}_{2}^{c} \mu^{d}+\tilde{\psi}_{3}^{c} \Sigma_{\mu}^{s}+\tilde{\psi}_{4}^{c} \Sigma_{\mu}^{d}
$$

We suppose, as usual, that the CCB is more concerned with inflation stabilization than society $(\tilde{\lambda} \leq \lambda)$.

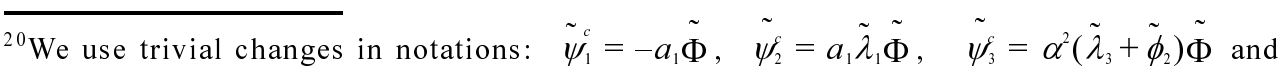
$\tilde{\psi}_{4}^{c}=\alpha^{2}\left(\tilde{\lambda}_{1}+\tilde{\phi}_{1}\right) \tilde{\Phi}, \quad$ with: $\quad \tilde{\phi}_{1}=\left(\alpha^{2}\left(\theta_{y}-\tilde{\lambda}\right)+\theta_{\pi}-1\right), \quad \tilde{\phi}_{2}=\left(\alpha \beta\left(\theta_{y}-\tilde{\lambda}\right)+1-\theta_{\pi}\right)$, $\tilde{\Phi}=1 /\left(\tilde{a}+a_{2} \tilde{\phi}_{1}\right)$, and $\tilde{a}=\tilde{\lambda}_{1} a / \lambda_{1}, \tilde{\lambda}_{3}=\alpha \beta \tilde{\lambda}-1, \tilde{\lambda}_{1}=1+\alpha^{2} \tilde{\lambda}, \tilde{\lambda}_{2}=1+\beta^{2} \tilde{\lambda}$.
} 


\section{Proposition 3:}

Suppose that there are only supply shocks $\left(\sigma_{\bar{\mu}_{i}^{d}}^{2}=\sigma_{\mu^{d}}^{2}=0, \forall i\right)$. If the CCB weights the stabilization of inflation relative to output more than social preferences in the Union (namely, if $\tilde{\lambda} \leq \lambda$ ), the first best solution for monetary policy can be obtained by a contract that penalizes the CCB from inflation and output divergences in the Union. In the optimal contract, the penalties imposed on inflation (respectively on output) divergences are higher than the relative weight of inflation (respectively output) in the social welfare function. Thus, the optimal contract for the CCB is such as: $\theta_{y}^{*} \geq \lambda$ and $\theta_{\pi}^{*} \geq 1$.

\section{Proof:}

The social loss resulting from the interest rule (13) is now: $E L^{U}\left(r^{c}\right)=\tilde{Z} \sigma_{\mu}^{2}+\tilde{Z} \sigma_{\bar{\mu}}^{2}$, where coefficients $\tilde{Z}$ and $\tilde{\bar{Z}}$ are computed in Appendix A. ${ }^{21}$ The differential of welfare associated with a centralized policymaking relative to a cooperative one is:

$$
\Delta E L=E L^{U}\left(r^{c}\right)-E L^{U}\left(r^{u}\right)=(\tilde{Z}-X) \sigma_{\mu}^{2}+(\tilde{\bar{Z}}-\bar{X}) \sigma_{\bar{\mu}}^{2}
$$

where: $\tilde{Z}-X=\frac{a_{1}}{2 \alpha^{2} a}\left[a_{2} \phi_{1}-\alpha^{2} a_{1}(\lambda-\tilde{\lambda})\right]^{2} \tilde{\Phi}^{2} \geq 0$ and

$$
\tilde{\bar{Z}}-\bar{X}=\frac{a_{2}}{2 a}\left[(\alpha+\beta)\left[\lambda_{1} \phi_{2}+\alpha^{2} \lambda_{3}(\lambda-\tilde{\lambda})\right]+\alpha a_{2} \phi_{3}\right]^{2} \tilde{\Phi}^{2} \geq 0
$$

If $\tilde{\lambda}=\lambda=\theta_{y}$ and $\theta_{\pi}=1$, the differential of welfare is zero. But if $\tilde{\lambda} \leq \lambda$, the differential of welfare is positive even if $\theta_{y}=\tilde{\lambda}$ and $\theta_{\pi}=1 .{ }^{22}$ Consequently, $\theta_{y}=\tilde{\lambda}$ and $\theta_{\pi}=1$ does not describe an optimal contract for monetary policy.

Concerning the symmetric component of supply shocks $\left(\sigma_{\bar{\mu}}^{2}=0\right)$, a centralized regime with aversion to divergences produces the same social loss as the optimal regime if:

$$
\theta_{\pi}=\theta_{\pi}=1-\alpha^{2}\left(\theta_{y}-\lambda\right)+\alpha^{2} \frac{a_{1}}{a_{2}}(\lambda-\tilde{\lambda})
$$

Concerning the asymmetric component of supply shocks (i.e. if $\sigma_{\mu}^{2}=0$ ), we obtain the same social loss under both regimes if:

\footnotetext{
$\overline{{ }^{21} \text { We can easily verify that: }} \tilde{Z}=Z, \tilde{\bar{Z}}=\bar{Z}$ if $\lambda=\tilde{\lambda}$.

${ }^{22}$ We obtain: $\tilde{Z}-X=\frac{a_{1} \alpha^{2}(\lambda-\tilde{\lambda})^{2}}{2 a \tilde{\lambda}_{1}^{2}} \geq 0$ and $\tilde{\bar{Z}}-\bar{X}=\frac{a_{2} \alpha^{2}(\lambda-\tilde{\lambda})^{2}}{2 a \tilde{\lambda}_{1}^{2}}$ if $\theta_{y}=\tilde{\lambda}$ and $\theta_{\pi}=1$.
} 


$$
\theta_{\pi}=\theta_{\pi}^{a}=1+\alpha^{2}\left[\Omega\left(\theta_{y}-\lambda\right)+\frac{\alpha(\alpha+\beta) \lambda_{3}(\lambda-\bar{\lambda})}{\alpha(\alpha+\beta) \lambda_{3}+\alpha^{2} a_{2} \lambda}\right]
$$

From (15)-(16), we easily obtain the values of the coefficients of aversion towards output and inflation divergences under the optimal contract.

$$
\theta_{y}^{*}=\lambda+\frac{(\alpha+\beta)}{\alpha \Sigma^{2}}(\lambda-\tilde{\lambda})>\lambda \text { and } \theta_{\pi}^{*}=1+\left[\frac{\beta(\alpha+\beta)}{\Sigma^{2}}\right](\lambda-\tilde{\lambda})>1
$$

The interpretation of Proposition 3 is the following. With independent preferences of the CCB $(\tilde{\lambda} \neq \lambda)$ and centralized policymaking, monetary policy is affected by two biases: one associated with the centralized policymaking and another one associated with independent preferences for the stabilization of output relative to inflation. Sufficiently high values of penalties allow removing these two biases simultaneously.

Optimal penalties in relations (17) are the sum of optimal penalties of the previous section (without independent preferences) and some "extra-penalties" ( $\theta^{*}-\lambda$ and $\left.\theta^{*}-1\right)$, which depend on the gap between the CCB and social preferences for output stabilization $(\lambda-\tilde{\lambda})$. These extra-penalties negatively respond to the degree of Union heterogeneity $\left(\Sigma^{2}\right)$, so that the optimal values of aversion towards inflation and output divergences are decreasing function of $\Sigma^{2}$ : the more heterogeneous the Union is, the lesser the CCB should worry about inflation and output divergences under the optimal contract. ${ }^{23}$

Let us examine more closely this apparent paradox. If the Union was homogenous, no optimal contract could be reached, because the common interest rate cannot affect cross-countries standard-error of inflation and output. ${ }^{24}$ Thus, no finite value of penalties $\theta_{\pi}$ or $\theta_{y}$ could totally remove the bias associated with the "wrong" CCB loss function, as show the values of penalties in equation (17), which tend to infinity. In a heterogeneous Monetary Union, on the contrary, penalties on divergences can modify the behaviour of the CCB. In other words, heterogeneity gives an instrument for correcting the bias associated with the "wrong" preference parameter $\tilde{\lambda}$.

\footnotetext{
${ }^{23}$ These "extra-penalties" also positively depend on $\alpha, \beta$ coefficients, suggesting that higher sensibility of the national variables to shocks induces more heterogeneity in the model, which asks for higher penalties in order to be corrected.

${ }^{24}$ If the Union is homogenous, penalties on divergences cannot change the response of "centralized" interest rate $\left(r^{c}\right)$ to shocks, and the equality $r^{c}=r^{u}$ can never be reached with $\lambda \neq \lambda$. Thus, optimal penalties in (17) go to infinity if $\Sigma^{2} \rightarrow 0$.
} 


\section{Second-Best Contracts for Monetary Policy}

However, the optimal contract does not seem to characterize the behaviour of the ECB. In the Euro area, the recent monetary policy debate has focused on the difficulties to define a suitable policy in the presence of inflation differentials, but with few references to income divergences. Moreover, it seems difficult to design monetary policy in function of output-gap differentials in EMU, since these differentials reflect structural adjustment and catching up of less developed Member States, and are outside the province of current interest rate policy. Even if inflation divergences also possess a structural component, they directly affect the CCB ability to define a "good" inflation rate for the area, and the ECB does probably keep more watch on inflation differentials than on output differentials.

In what follows, we search for a "second best" contract, when the CCB shares the social relative preferences for output and inflation stabilization $(\tilde{\lambda}=\lambda)$, as in sections II and III, and worries about inflation differentials, but is not endowed with the optimal degree of aversion to output divergences $\left(\theta_{y} \neq \theta_{y}^{*}=\lambda\right)$. In fact, we seek the optimal degree of aversion to inflation divergences, given the degree of aversion to output divergences (possibly zero).

Relations (15) and (16) already exhibit the best value of $\theta_{\pi}$ in function of $\theta_{y}$, in two special cases: with symmetric shocks only $\left(\sigma_{\bar{\mu}}^{2}=0\right.$ for 15$)$ or with asymmetric shocks only ( $\sigma_{\bar{\mu}}^{2}=0$ for 16 ). Now, we search for the best reaction function $\theta_{\pi}=f\left(\theta_{y}\right)$ in the general case with both symmetric and asymmetric shocks. Notice that the slope of this reaction function depends on the relative sizes of symmetric and asymmetric shocks, since the reaction function is decreasing in the presence of symmetric shocks only (15) and increasing if there are asymmetric shocks only (16). Let us denote by $\sigma=\sigma_{\bar{\mu}}^{2} / \sigma_{\mu}^{2}$ the ratio of variances of asymmetric to symmetric shocks (i.e. the relative "size" of asymmetric to symmetric shocks). With both symmetric and asymmetric shocks, one can express the degree of aversion to inflation divergences $\left(\theta_{\pi}^{*}\right)$ that minimizes the welfare differential, for a given coefficient of aversion for output divergences $\left(\theta_{y}\right)$ as: $:^{25}$

$$
\theta_{\pi}^{*}-1=\Theta\left(\theta_{y}-\lambda\right)
$$

\footnotetext{
${ }^{25}$ In this expression: $\Theta=\frac{-a_{1} a_{2}+\alpha\left(a_{2}+(\alpha+\beta) \beta \lambda_{1}\right)\left[(\alpha+\beta) \lambda_{1}+\alpha a_{2} \theta_{y}\right] \sigma}{a_{1}\left(\Sigma^{2}+\lambda_{1}^{2} \sigma\right)+a_{2} \alpha\left[(\alpha+\beta) \lambda \lambda_{1}+\theta_{y}\left((\alpha+\beta) \lambda_{1}+\alpha a_{2} \lambda\right)\right] \sigma}$. Relation (18) is obtained by minimizing (14) with respect to $\theta_{\pi}, \theta_{y}$ given.
} 
Coefficient $\Theta$ depends on the variance of symmetric and asymmetric $\operatorname{shocks}(\sigma)$, but for admissible parameter values, asymmetric shocks dominate, even if their variance is very small compared to that of symmetric shocks. So, the relation between $\theta_{y}$ and $\theta_{\pi}^{*}$ is most probably positive. Figure 1 , which represents $\theta_{\pi}^{*}$ as a function of $\theta_{y}$, for different ratios $\sigma=\sigma_{\bar{\mu}}^{2} / \sigma_{\mu}^{2}$, and for different values of $\lambda$, depicts this fact. If there are no asymmetric shocks in the model $(\sigma=0)$, relation (18) is negatively sloped, but it becomes positively sloped for lower values of $\sigma$ (as soon as $\sigma \geq 0.02$, if $\lambda=1$, for example).

Figure 1. Best value for $\theta_{\pi}$ in function of $\theta_{y}{ }^{26}$
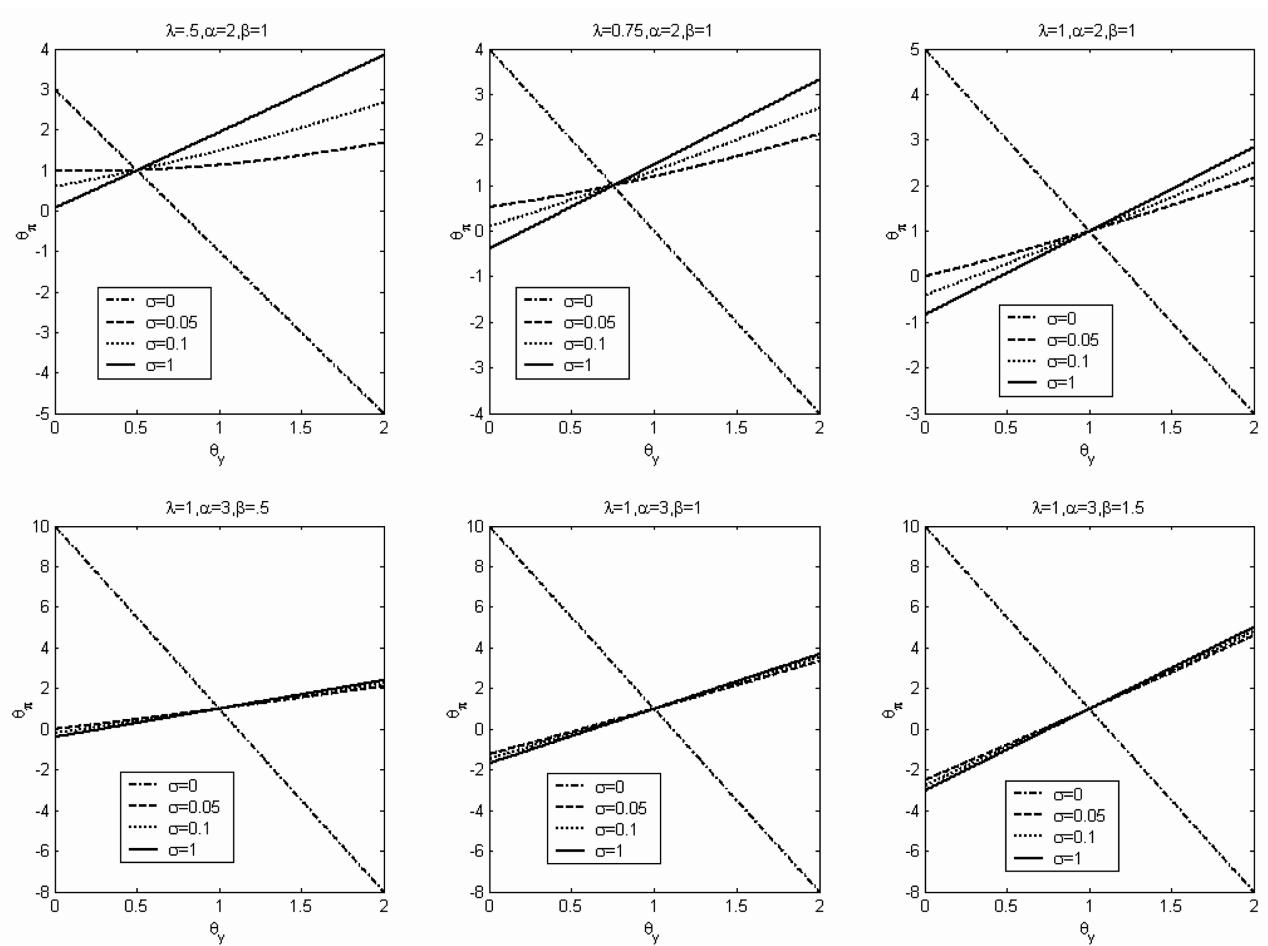

\footnotetext{
${ }^{26}$ The simulations are calibrated by considering reasonable values for parameters. Taking into account the microfounded determination of the national supply functions used in the model, the values of coefficient $\alpha$ (see, 2 or 3 in our simulations) reflect standard values for the labor elasticity of supply (between 3/4 and 2/3) and are close to the empirical estimations provided by Hartley \& Whitt Jr. (2003) for the European countries. Empirical estimations for $\beta$ in Euro countries are in the interval. We choose the medium value $\beta=1$. Under the assumption that the $\mathrm{CCB}$ is more concerned with the inflation stabilization than with the output stabilization, we considered $\lambda<1$. We generally take a mediumdegree of heterogeneity $\Sigma^{2}=0.25$, but considering different degree of heterogeneity (between $0.25^{2}$ and 1 , for example) does not significantly change the results of our simulations.
} 
Furthermore, when the CCB does not care about output divergences $\left(\theta_{y}=0\right)$, solving the problem of asymmetric shocks may require a negative optimal degree of aversion to inflation divergences ( columns of Figure 1, for example). Thus, from the Union-wide welfare perspective, a CCB that worries about inflation divergences, but neglects output differentials might not be a good idea.

The model shows that a CCB that focuses on inflation differential, and disregards output differential may be detrimental to the Union welfare, especially if the Union is stricken by large asymmetric shocks (graphs on the last two columns in Figure 1). On the contrary, in some cases, if symmetric shocks are large enough compared to asymmetric shocks (graphs on the first column in Figure 1), a contract that penalizes the CCB only for inflation divergences could be beneficial to the Union welfare. This analysis proves the importance of taking into account the nature of shocks in assessing the welfare gains associated to different institutional arrangements.

\section{Conclusion}

This paper studies the optimal monetary policy design in a heterogeneous monetary union with national divergences arising not only from idiosyncratic shocks but also from structural asymmetries into the transmission channel of monetary policy among Member States. The main question is: Should a CCB in a heterogeneous Monetary Union worry about inflation and output differentials? Our answer is positive and we show that an optimal contract, able to maximize the Union-wide welfare does exist for the CCB. This contract imposes penalties on the CCB for inflation and output divergences in the Union and simply describes the fact that the CCB must be forced, implicitly or explicitly, to watch closely over the divergences within the Union. Besides, penalizing the CCB only for inflation divergences is not necessarily a better solution than a "centralized" policymaking based only on Union-wide variables.

The features of the optimal contract are not much complicated than those of the optimal contract derived by Walsh (1995) to solve a credibility problem of monetary policy, which results in a linear penalty on inflation. The main difference between the Walsh (1995) and our study is that we address the stabilization problem of the monetary policy, using linear penalties on inflation and output divergences. All different propositions for the implementation of the Walsh's 
contract in practice could be simply transposed to discuss the implementation of our "optimal contract". The solution could be derived from the appointment of a divergence-adverse central banker, as in Rogoff (1985), the setting of divergencetargets for the monetary policy, as in Svensson (1997), or the explicit or implicit contracts for the CCB with divergences oriented penalties, as in Walsh (1995). ${ }^{27}$

However, the optimal contract found in this paper is open to usual criticisms addressed to contractual literature in monetary policy. Its implementation is made difficult, because only some Member States take advantage of this contract, while it is detrimental to the welfare of others. ${ }^{28}$ Modifying CCB preferences can therefore be a source of conflicts among Member States of the Union.

In our model, structural heterogeneity is only introduced in the transmission of the monetary policy. However other structural asymmetries reflecting different level of economic development during the catching up process within the Union could be also studied. Thus, this work can be viewed as a first step towards more general frameworks. It should be interesting to extend the present analysis to an open Monetary Union, to see how exchanges with foreign countries affect penalties on national divergences. Studying more explicitly the different channels of heterogeneity in the Union could also produce interesting results about the form of the contract for the CCB. Finally, we could investigate how the optimal contract for the $\mathrm{CCB}$ in a heterogeneous Union is affected by the behaviour of national governments, in a framework where governments minimize their own loss function. Such extensions are unlikely to modify the optimal contract for the CCB, which is not model dependent, but may improve the analysis in a second best world.

\section{Acknowledgements}

The authors would like to thank Jean-Paul Pollin, Grégory Levieuge and the two anonymous referees for very useful remarks on previous versions of this paper. The usual disclaimer applies.

\footnotetext{
${ }^{27}$ Penalties can be of financial or "political" (loss of credibility of the central bank, conflicts with Member States of the Union,...) nature. Walsh (2001) discusses in some details different institutional arrangements that corresponds in practice to contracts for central banker, in particular the "Policy Target Agreement » established in 1989 in New Zealand.

${ }^{29}$ Furthermore, it is difficult to identify which countries take benefits from the contractual solution in practical terms, since estimations of the interest-elasticity of global demand in the Euro zone are very imprecise (see Mojon \& Peersman (2001), for example).
} 


\section{Appendix}

\section{A. Resolution of the Model}

- Optimal interest rate: The first order condition for the minimisation of (6) is: $\frac{d L^{U}}{d r}=0$. We then use $\int_{0}^{1} \varepsilon_{i} d i=0$ and $\int_{0}^{1} b_{i} d i=b$, implying: $\int_{0}^{1} b_{i} \bar{\mu}_{i}^{s} d i=b \int_{0}^{1} \varepsilon_{i} \bar{\mu}_{i}^{s} d i$ $\equiv \int_{i}^{1} b_{i}^{2} d i=b^{2}\left(1+\Sigma^{2}\right) \quad$ and, $\int_{0}^{1} b_{i} \bar{\mu}_{i}^{d} d i=b \int_{0}^{1} \varepsilon_{i} \bar{\mu}_{i}^{d} d i \equiv b \Sigma_{\mu}^{d}$ to write the optimal interest

rate:

Since aggregate demand depends on, equilibrium solutions are independent of $b$, and we can normalize $b=1$ (the same reasoning applies for the centralized regime). By setting: $a_{1}=(\alpha+\beta)^{2}, a_{2}=\alpha^{2} \Sigma^{2}$ and $a=\lambda_{1}\left(a_{1}+a_{2}\right)$, we find equation (9) of the main text.

- Centralized interest rate: The minimization of (12) asks for: $\frac{d L^{c}}{d r}=0$. Since: $\int_{0}^{1}\left(b-b_{i}\right) d i=0, \quad \int_{0}^{1}\left(b-b_{i}\right)^{2} d i=b^{2} \Sigma^{2}, \quad \int_{0}^{1}\left(b-b_{i}\right) \bar{\mu}_{i}^{s} d i=-b \Sigma_{\mu}^{s}, \quad$ and $:$ $\int_{0}^{q}\left(b-b_{i}\right) \bar{\mu}_{i}^{d} d i=-b \Sigma_{\mu}^{d}$, we obtain:

$b r^{c}=\frac{(\alpha+\beta)^{2}\left(\lambda_{1} \mu^{d}-\mu^{s}\right)+\alpha^{2}\left[\left(\theta_{\pi}+\theta_{y} \alpha^{2}\right) \Sigma_{\mu}^{d}+\left(\alpha \lambda \theta_{v}-\theta_{\pi}\right) \Sigma_{\mu}^{s}\right]}{(\alpha+\beta)^{2} \lambda_{1}+\alpha^{2}\left(\theta_{\pi}+\theta_{y} \alpha^{2}\right) \Sigma^{2}}$.

By setting: $b=1, \phi_{1}=\alpha^{2}\left(\theta_{y}-\lambda\right)+\theta_{\pi}-1$ and $\phi_{2}=\alpha \beta\left(\theta_{y}-\lambda\right)-\left(\theta_{\pi}-1\right)$ we find equation (14) of the paper. If $\theta_{y}=\theta_{\pi}=0$, then $\lambda_{3}+\phi_{2}=0$ and $\lambda_{1}+\phi_{1}=0$, and we find relation (8).

\section{B. Expected Social Loss}

Suppose first that there is no demand shock $\left(\mu^{d}=\bar{\mu}_{i}^{d}=0\right)$. To solve the model, we use the same procedure for all regimes: optimal ('cooperative') regime, centralized regime, centralized regime with aversion to divergences for $(\tilde{\lambda}=\lambda)$ or $(\tilde{\lambda} \neq \lambda)$. Using equations (9), (8), (13) and (13) respectively, we obtain the equilibrium values of inflation and output in (3a), (3b), (4a) and (4b), that we replace in the corresponding expected social loss. The resolution procedure and notations are detailed in our Technical Appendix.

- Centralized regime: 


$$
E L^{U}\left(r^{c}\right)=\int_{0}^{1} E L^{i}\left(r^{c}\right) d i=\frac{1}{2 \alpha^{2}}\left(1-\frac{a_{1}-a_{2}}{\lambda_{1} a_{1}}\right) \sigma_{\mu}^{2}+\frac{\lambda_{2}}{2 a_{1}} \sigma_{\bar{\mu}}^{2}
$$

where $\sigma_{\bar{\mu}}^{2}=\int_{0}^{1} \sigma_{\bar{\mu}_{i}}^{2} d i$ denotes the variance of asymmetric supply shocks.

With: $Y=\frac{\left(\lambda_{1} a_{1}-\left(a_{1}-a_{2}\right)\right)}{2 \alpha^{2} \lambda_{1} a_{1}}$ and: $\bar{Y}=\lambda_{2} / 2 a_{1}$, we find: $E L^{U}\left(r^{c}\right)=Y \sigma_{\mu}^{2}+\bar{Y} \sigma_{\bar{\mu}}^{2}$.

- Optimal regime:

$$
E L^{U}\left(r^{u}\right)=\frac{a-a_{1}}{2 a \alpha^{2}} \sigma_{\mu}^{2}+\frac{\lambda_{2}}{2 a_{1}} \sigma_{\bar{\mu}}^{2}-\frac{\alpha^{2}\left(\lambda_{3}\right)^{2}}{2 a_{1} a} E\left(\Sigma_{\mu}^{s}\right)^{2}
$$

Setting: $X=\left(a-a_{1}\right) / 2 a \alpha^{2}, \bar{X}=\left(\lambda_{2} a-a_{2} \lambda_{3}^{2}\right) / 2 a_{1} a$, and in the special case of i) independently distributed asymmetric supply shocks $\left(\sigma_{\vec{\mu}_{i}} \sigma_{\vec{\mu}_{j}}=0\right)$, ii) same variance of supply shocks in all countries $\left(\sigma_{\vec{\mu}_{i}}^{2}=\sigma_{\bar{\mu}}^{2} \quad \forall i\right)$, we find: $E L^{U}\left(r^{u}\right)=X \sigma_{\mu}^{2}+\bar{X} \sigma_{\bar{\mu}}^{2}$, since: $E\left(\Sigma_{\mu}^{s}\right)^{2}=\sigma_{\bar{\mu}}^{2} \int_{0}^{2} \varepsilon_{i}^{2} d i=\Sigma^{2} \sigma_{\bar{\mu}}^{2}$. As we shall see in this Appendix, all results in the main text hold independently of these two assumptions.

- Centralized regime with aversion towards divergences $(\tilde{\lambda}=\lambda)$ :

$$
\begin{gathered}
E L^{U}\left(r^{c}\right)=\left[\frac{1-a_{1}\left(a+2 a_{2} \phi_{1}\right) \Phi^{2}}{2 \alpha^{2}}\right] \sigma_{\mu}^{2}+\frac{\lambda_{2}}{2 a_{1}} \sigma_{\bar{\mu}}^{2}- \\
{\left[\left(a+2 a_{2} \phi_{1}\right) \lambda_{3}-a \phi_{2}\right] \frac{\alpha^{2}\left(\lambda_{3}+\phi_{2}\right) \Phi^{2}}{2 a_{1}} E\left(\Sigma_{\mu}^{3}\right)^{2}}
\end{gathered}
$$

Under i) and ii) above, and using the following notations: $\mathrm{Z}=\left[1-a_{1}\left(a+2 a_{2} \phi_{1}\right) \Phi^{2}\right] /$ $2 \alpha^{2}$, and: $\bar{Z}=\left\{\lambda_{2}-a_{2}\left(\phi_{2}+\lambda_{3}\right)\left[\left(a+2 a_{2} \phi_{1}\right) \lambda_{3}-a \phi_{2}\right] \Phi^{2}\right\} / 2 a_{1}$, one can easily find: $E L^{U}\left(r^{s}\right)=Z \sigma_{\mu}^{2}+\bar{Z} \sigma_{\bar{\mu}}^{2}$.

- Centralized regime with aversion towards divergences $(\tilde{\lambda} \neq \lambda)$ :

$$
\begin{gathered}
E L^{U}\left(r^{c}\right)=\frac{1}{2 \alpha^{2}}\left[1-\tilde{a}_{1} \tilde{\Phi}^{2}\left[a+2\left(a_{2} \phi_{1}-a_{1} \alpha^{2}(\lambda-\tilde{\lambda})\right)\right]\right] \sigma_{\mu}^{2}+\frac{\lambda_{2}}{2 a_{1}} \sigma_{\bar{\mu}}^{2} \\
-\left[a\left(\tilde{\lambda}_{3}+\tilde{\phi}_{2}\right)-2 \lambda_{3}\left(\tilde{a}+a_{2} \tilde{\phi}_{1}\right)\right] \frac{\alpha^{2}\left(\tilde{\lambda}_{3}+\tilde{\phi}_{2}\right) \tilde{\Phi}^{2}}{2 a_{1}} E\left(\Sigma_{\mu}^{s}\right)^{2}
\end{gathered}
$$

Under i) and ii) and using: $\tilde{\lambda}_{3}+\tilde{\phi}_{2}=\lambda_{3}+\phi_{2}$, one can easily find: $E L^{U}\left(\underline{r}^{c}\right)=\tilde{Z} \sigma_{\mu}^{2}+\tilde{\bar{Z}} \sigma_{\bar{\mu}}^{2}$, by setting: $\tilde{\tilde{Z}}=\left\{1-a_{1}\left[a+2\left(a_{2} \phi_{1}-a_{1} \alpha^{2}(\lambda-\tilde{\lambda}-\tilde{\lambda})\right)\right] \Phi^{2}\right\} / 2 \alpha^{2}$, and $\tilde{\bar{Z}}=\left\{\lambda_{2}-a_{2}\left(\phi_{2}+\lambda_{3}\right)\left[\lambda_{3}\left(2 a_{2} \tilde{\phi}_{1}+\tilde{a}-\alpha^{2}\left(a_{1}+a_{2}\right)(\lambda-\tilde{\lambda})\right)-a \phi_{2}\right] \Phi \Phi^{2}\right\} / 2 a_{1}$.

Welfare differentials $\left(\triangle E L=E L^{U}\left(r^{c}\right)-E L^{U}\left(r^{u}\right)\right)$

One can find equation (10) of the main text by computing (A1)-(A2): 


$$
\Delta E L=\left(\frac{\lambda_{1} a_{2}^{2}}{2 \alpha^{2} \lambda_{1} a_{1} a}\right) \sigma_{\mu}^{2}+\frac{\alpha^{2}\left(\lambda_{3}\right)^{2}}{2 a_{1} a} E\left(\Sigma_{\mu}^{s}\right)^{2}>0
$$

From (A3)-(A2), we obtain the social-loss differential (14) with aversion to divergences:

$$
\Delta E L=\left(\frac{a_{1} a_{2}^{2} \phi_{1}^{2} \Phi^{2}}{2 \alpha^{2} a}\right) \sigma_{\mu}^{2}+\frac{1}{2 a_{1}}\left(\frac{\alpha^{2} \lambda_{3}^{2}}{a}-\left[\left(a+2 a_{2} \phi_{1}\right) \lambda_{3}-a \phi_{2}\right] \alpha^{2}\left(\lambda_{3}+\phi_{2}\right) \Phi^{2}\right) E\left(\Sigma_{\mu}^{s}\right)^{2}(\mathrm{~A} 6)
$$

Finally, (A4)-(A2) gives the social-loss differential (14') with aversion to divergences and $\mathrm{CCB}$ own preferences:

$$
\begin{gathered}
\Delta E L=\left(\frac{a_{1}}{2 \alpha^{2} a}\left[a_{2} \phi_{1}-\alpha^{2} a_{1}(\lambda-\tilde{\lambda})\right]^{2} \tilde{\Phi}^{2}\right) \sigma_{\mu}^{2} \\
+\frac{\alpha^{2}}{2 a}\left[(\alpha+\beta)\left[\lambda_{1} \phi_{2}+\alpha^{2} \lambda_{3}(\lambda-\tilde{\lambda})\right]+\alpha \alpha_{2} \phi_{3}\right]^{2} \tilde{\Phi}^{2} E\left(\Sigma_{\mu}^{s}\right)^{2}
\end{gathered}
$$

Relations (10), (14) and (14') are computed owning to the assumption: $E\left[\left(\Sigma_{\mu}^{s}\right)^{2}\right]=\Sigma^{2} \sigma_{\bar{\mu}}^{2}$. Relations (A5), (A6) and (A7) are more general and do not depend on assumptions i) and ii) above, thus generalizing our main text findings.

\section{Welfare Differential for Country $i$}

In the centralized regime with aversion towards divergences, we note: $q_{i}=\beta+\alpha\left(1+\varepsilon_{i}\right)$, and the ex ante social loss for country $i$ is:

$$
\begin{gathered}
E L_{i}=\frac{1}{2}\left[\frac{\left[q_{i} a_{1} \Phi-(\alpha+\beta)\right]^{2}}{\alpha^{2} a_{1}}+a_{1} \lambda q_{i} \Phi^{2}\right] \sigma_{\mu}^{2}+ \\
+\frac{1}{2}\left[\frac{\lambda_{2}+q_{i} \alpha \Phi\left(\lambda_{3}+\phi_{2}\right)\left[2 \varepsilon_{i}+q_{i} \alpha \lambda_{1} \Sigma^{2} \Phi\left(\lambda_{3}+\phi_{2}\right)-2 \alpha \beta \lambda \varepsilon_{i}\right]}{a_{1}}\right] \sigma_{\bar{\mu}}^{2}
\end{gathered}
$$

For the centralized monetary policy without penalty $\left(\theta_{\pi}=\theta_{y}=0\right)$, we replace: $\phi_{1}=-\lambda_{1}, \phi_{2}=-\lambda_{3}$ and $\Phi=1 / \lambda_{1} a_{1}$ in (B1) to obtain the social loss function $E L_{i}^{c}$, while under the optimal regime, the social loss $E L_{i}^{u}$ is found by replacing in (B1): $\phi_{1}=0$, and $\Phi=1 / a$.

The national welfare loss differential $\left(\Delta E L_{i}=E L_{i}^{c}-E L_{i}^{u}\right)$ can be simplified to: $\Delta E L_{i}=\left(\varepsilon_{i}-\bar{\varepsilon}\right) \frac{\left(2 a_{1}+a_{2}\right) \alpha q_{i} \lambda_{1}}{2 a^{2} a_{1}}\left[\Sigma^{2} \sigma_{\mu}^{2}+\lambda_{3}^{2} \sigma_{\bar{\mu}}^{2}\right]$, where: $\bar{\varepsilon}=\frac{\alpha(\alpha+\beta) \Sigma^{2}}{2(\alpha+\beta)^{2}+\alpha^{2} \Sigma^{2}} \in[0,1]$. 


\section{References}

Angelini, P., Del Giovane, P., Siviero, S. and D. Terlizzese(2002), "Monetary Policy Rules for the Euro Area: What Role for National Information?", Banca d' Italia Temi di Discussione no. 457.

Angeloni, I. and M. Ehrmann(2004), "Euro Area Inflation Differentials", European Central Bank, Working Paper No. 388.

Aksoy, Y., De Grauwe, P. and H. Dewachter(2002), "Do Asymmetries Matter for European Monetary Policy?", European Economic Review, 46(3), pp. 443-469.

Badarau-Semenescu, C., Gregoriadis, N. and P. Villieu(2008), "Monetary Policy Transmission Asymmetries in a Heterogeneous Monetary Union: a Simple Contractual Solution", Economics Bulletin, 5(20), p. 1-7.

Brissimis, S. N. and Skotida, I.(2008), "Optimal Monetary Policy in the Euro Area in Presence of Heterogeneity", Journal of International Money and Finance, 27, pp. 209-226.

De Grauwe, P.(2007), “Economics of Monetary Union"(7th Ed.), Oxford University Press.

De Grauwe, P.(2000), "Monetary Policy in the Presence of Asymmetries", Journal of Common Market Studies, 38(4), pp. 593-612.

De Grauwe, P. and Piskorski, T.(2001), "Union-wide Aggregates Versus National Data Based Monetary Policies: does it Matter for the Eurosystem?", CEPR discussion paper no. 3036.

De Grauwe, P. and A. Senegas(2006), "Monetary Policy Design and Transmission Asymmetry in EMU: does Uncertainty Matter?", European Journal of Political Economy, 22, pp. 787-808.

Gali, J. and T. Monacelli(2008), "Optimal Monetary and Fiscal Policy in a Currency Union", Journal of International Economics, 76, pp. 116-132.

Gros, D. and C. Hefeker(2007), "Monetary Policy in EMU with Asymmetric Transmission and Non-tradable Goods", Scottish Journal of Political Economy, 54(2), pp. 268-282.

Gros, D. and C. Hefeke(2002), "One Size must Fit All: National Divergences in a Monetary Union", German Economy Review, 3(3), pp. 1-16.

Hartley P. R. and J. A. Whitt Jr.(2003), "Macroeconomic Fluctuations: Demand or Supply, Permanent or Temporary?", European Economic Review, 47, pp. 61-94.

Hefeker, C.(2004), "Uncertainty, Wage Setting and Decision Making in a Monetary Union", Hamburg Institute of International Economics, Discussion Paper 272.

Heinemann, F. and F. Hüfner(2004), "Is the View from the Eurotower Purely European? National Divergence and ECB Interest Rate Policy", Scottish Journal of Political Economy, 51, pp. 544-58.

Herrendorf B. and D. Lockwood(1997), "Rogoff's 'Conservative' Central Banker Restored", Journal of Money, Credit and Banking, 29, pp. 473-491.

Issing, O., Gaspar, V., Angeloni, I. and O. Tristani(2001), "Monetary Policy in the Euro- 
Area: Strategy and Decision-making at the European Central Bank", Cambridge University Press, Cambridge.

Menguy, S.(2008), "Dilemma of One Common Central Bank in a Heterogeneous Monetary Union", Journal of Economic Integration, 23(4), pp. 791-816.

Minea A. and P. Villieu(2009), "Threshold Effects in Monetary and Fiscal Policies in a Growth Model", Journal of Macroeconomics, 31, pp. 304-319.

Mojon, B. and G. Peersman(2001), "A VAR Description of the Effects of Monetary Policy in the Individual Countries of the Euro-Area", European Central Bank, Working Papers Series 92.

Monteforte, L. and S. Siviero,(2002), "The Economic Consequences of Euro Area Modelling Shortcuts", Banca d' Italia Temi di Discussione no. 458.

Musso, A. and T. Westermann(2005), "Assessing Potential Output Growth in the EuroArea: a Growth Accounting Perspective", European Central bank, Occasional Paper Series No.22.

Rogoff, K.(1985), "The Optimal Degree of Commitment to a Monetary Target", Quarterly Journal of Economics, 100, pp. 1169-1990.

Svensson L. EO.(1997): "Optimal Inflation Targets, Conservative Central Banks and Linear Inflation Contracts", American Economic Review, 87, pp. 98-114.

Walsh, Carl E.(1995), "Optimal Contracts for Central Bankers", American Economic Review, March, 85(1), pp. 150-167.

Walsh, Carl E.(2001), "Monetary Theory and Policy", The MIT Press. 